\title{
Características físicas, químicas e físico-químicas dos frutos da murta
}

\author{
Physical and physico-chemical fruits characteristics of myrtle
}

\author{
Dyalla Ribeiro de Araujo ${ }^{1}$, Eliseu Marlônio Pereira de Lucena ${ }^{2}$, Josivanda Palmeira Gomes $^{3}$, Rossana Maria Feitosa de \\ Figueirêdo ${ }^{3}$, Érllens Eder Silva ${ }^{1}$
}

Resumo: O presente trabalho teve como objetivo estudar as características físicas, químicas e físico-químicas dos frutos da murta (Eugenia gracillima Kiaersk.) no estádio de maturação "maduro". Os frutos de murta foram colhidos em área de vegetação nativa, na propriedade rural da família Lermen, localizada na Serra dos Paus Dóias - Chapada do Araripe, município de Exu, PE. Após a colheita, os frutos foram transportados para o Laboratório de Ecofisiologia Vegetal da Universidade Estadual do Ceará, para a realização das análises físicas, químicas e físico-químicas: coloração da casca; diâmetros longitudinal e transversal; massas fresca, seca e de água e teor de água; sólidos solúveis totais (SST), acidez total titulável (ATT), pH, relação SST/ATT, carboidratos (amido, açúcares solúveis totais, açúcares redutores e açúcares não redutores); vitamina C; pectinas; fenólicos; antocianinas; flavonoides amarelos e carotenoides. Os frutos da murta (Eugenia gracillima Kiaersk.) são relativamente pequenos com formato levemente ovalado e com coloração $100 \%$ violeta quando maduros. Apresentaram ótima qualidade para consumo pelo conteúdo dos sólidos solúveis totais (15,08 ${ }^{\circ}$ Brix), relação SST/ATT $(18,37)$, açúcares solúveis totais $(11,61 \%)$ e açúcares redutores $(7,80 \%)$, como também são frutos ricos em vitamina C (160,62 $\mathrm{mg} / 100 \mathrm{~g}$ de massa fresca do fruto) e antioxidantes.

Palavras-chaves: Eugenia gracillima Kiaersk., fisiologia pós-colheita, frutificação.

Abstract: The present work aimed to study the physical, chemical and physico-chemical fruits characteristics of myrtle (Eugenia gracillima Kiaersk.) in maturation stage "mature". The fruits of myrtle were collected in an area of native vegetation in rural Lermen family property, located in the Serra dos Paus Dóias - Araripe, municipality of Exu, PE. After harvest, the fruits were transported to the Laboratory of Plant Ecophysiology, Ceará State University, to the achievement of physical, chemical and physico-chemical analysis: peel color; longitudinal and transverse diameters; fresh, dry mass and water content and water; total soluble solids (TSS), titulable total acidity (TTA), pH, TSS/TTA, carbohydrates (starch, total soluble sugars, reducing sugars and non reducing sugars, vitamin $\mathrm{C}$, pectins, phenolics, anthocyanins, yellow flavonoids and carotenoids. The myrtle fruit (Eugenia gracillima Kiaersk.) are relatively small with slightly oval in shape and staining with $100 \%$ purple when ripe. Showed excellent quality for consumption for the content of total soluble solids $\left(15.08^{\circ}\right.$ Brix), TSS/TTA (18.37), total soluble sugars $(11.61 \%)$ and reducing sugar $(7.80 \%)$, as well fruits are rich in vitamin C weight of fruit) and antioxidants.

Key words: Eugenia gracillima Kiaersk., postharvest physiology, fructification.

\footnotetext{
*Autor para correspondência

Recebido para publicação em 07/01/2015; aprovado em 02/07/2015

${ }^{1}$ IFCE Campus Crato. E-mail: dyalla@ifce.edu.br; erllens@ifce.edu.br

${ }^{2}$ Universidade Estadual do Ceará. E-mail: eliseu.lucena@uece.br

${ }^{3}$ Universidade Federal de Campina Grande. E-mail: josivanda@gmail.com; rossana@deag.ufcg.edu.br
} 


\section{INTRODUÇÃO}

A murta (Eugenia gracillima Kiaersk.) espécie nativa da Chapada do Araripe, vem sendo utilizada na forma de doces, geleias e licores por pequenos e médios agricultores, os quais praticamente não utilizam tecnologia avançada, mas sim práticas convencionais. Desta forma, o real potencial econômico da murta fica limitado, pois são desconhecidos: o momento ideal de colheita desses frutos, formas de armazenamento e técnicas que possibilitem um melhor aproveitamento dos frutos e sua comercialização, como também, a alta perecibilidade apresentada por este ocasiona durante seu armazenamento a diminuição de alguns atributos de qualidade comumente exigidos pelo mercado consumidor e significativas perdas pós-colheita.

$\mathrm{O}$ conhecimento a respeito das condições de cultivo e do ponto ideal de colheita torna-se essencial para que possam ser desenvolvidas técnicas adequadas na elaboração de estratégias eficientes, passíveis de auxiliar os produtores no manuseio, obtendo um produto com qualidade para a comercialização (CUNHA JÚNIOR et al., 2010). Assim como, as tecnologias pós-colheita, que fornecem perspectivas cada vez mais amplas e promissoras de atividade e agregação de renda por parte de agricultores familiares e extrativistas, aumentando o período de comercialização e reduzindo as perdas pós-colheita dos frutos nativos (CAMPOS et al., 2011).

O crescente interesse mundial por frutas nativas do Brasil tem impulsionado a realização de pesquisas, que vêm sendo intensificadas à medida que as têm comprovado os efeitos benéficos à saúde, exercidos por diversos fitoquímicos, naturalmente presentes nos vegetais.

Nesse sentido, objetivou-se, com o presente trabalho, estudar as características físicas, químicas e físico-químicas dos frutos da murta (Eugenia gracillima Kiaersk.) no estádio de maturação "maduro", de forma a contribuir para o desenvolvimento de tecnologias aplicadas a cadeia produtiva desta espécie.

\section{MATERIAL E MÉTODOS}

Os frutos de murta no estádio de maturação "maduro" foram colhidos em área de vegetação nativa, na propriedade rural da família Lermen, localizada na Serra dos Paus Dóias - Chapada do Araripe, município de Exu, PE (latitude $7^{\circ} 21^{\prime} \mathrm{S}$, longitude $39^{\circ} 53^{\prime} \mathrm{W}$ e altitude $884 \mathrm{~m}$ ), durante o ano agrícola de 2011/2012. Estes foram identificados no estádio de maturação "maduro" através da sua coloração (Figura 1), estádio este adotado para colheita dos frutos pelos produtores da Região.

Após a colheita, os frutos foram transportados para o Laboratório de Ecofisiologia Vegetal da Universidade Estadual do Ceará, onde foram realizadas as avaliações físicas, químicas e físico-químicas: coloração da casca; diâmetros longitudinal e transversal; massas fresca, seca e de água e teor de água; sólidos solúveis totais (SST); acidez total titulável (ATT); pH; relação SST/ATT; carboidratos (amido, açúcares solúveis totais, açúcares redutores e açúcares não redutores); vitamina $\mathrm{C}$; pectinas; fenólicos; antocianinas totais; flavonoides amarelos e carotenoides totais.

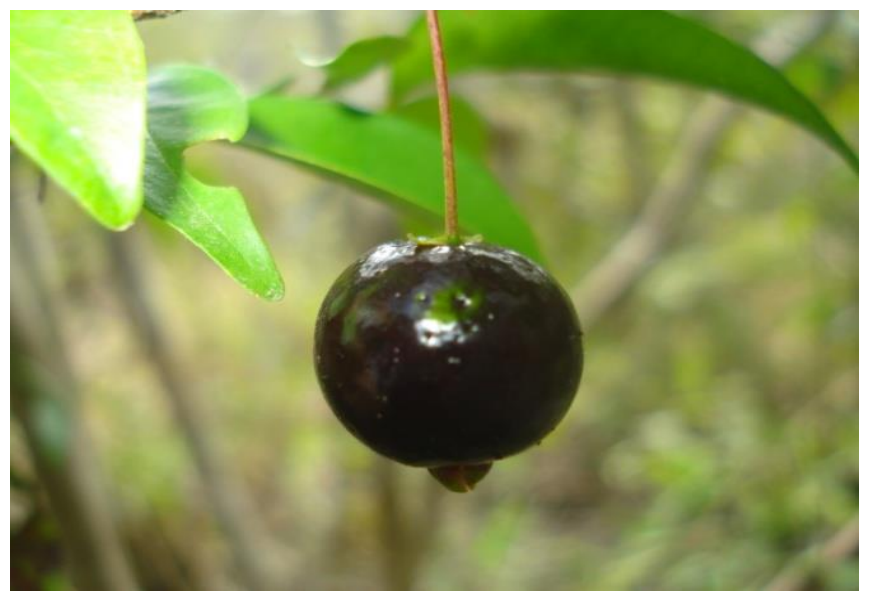

Figura 1. Fruto da murta (Eugenia gracillima Kiaersk.) no estádio de maturação "maduro" - Chapada do Araripe, Exu, PE.

A coloração da casca foi determinada com base na cartilha de Munsell (1994), que expressa a cor em três parâmetros: valor $(\mathrm{V})$, que corresponde à luminosidade, brilho, claridade ou reflectância (0-escuro/opaco e 100branco); croma (C), refere-se à saturação ou intensidade da cor (0-cor impura e 60-cor pura) e ângulo Hue $(\mathrm{H})$, relacionado ao ângulo da cor $\left(0^{\circ}\right.$-vermelha, $90^{\circ}$ - amarelo, $180^{\circ}$ - verde, $270^{\circ}$ - azul e $360^{\circ}$ - negro) .

Os diâmetros foram determinados mediante o uso de um paquímetro digital modelo SC-6 com escala graduada em milímetros (precisão de $0,1 \mathrm{~mm}$ ). Os resultados foram expressos milímetros (mm).

Para determinação da massa fresca foram escolhidos, aleatoriamente, 10 frutos, os quais foram pesados em balança semianalítica com precisão de $0,1 \mathrm{~g}$; os resultados foram divididos por 10 (número de frutos utilizados na pesagem) para obtenção da massa fresca/fruto, expressa em grama (g) (LUCENA et. al., 2007).

Visando à determinação da massa seca, os frutos utilizados na determinação da massa fresca foram fracionados e colocados para secar em estufa de circulação forçada de ar a $60 \pm 2{ }^{\circ} \mathrm{C}$ até a obtenção de massa constante determinada em balança semianalítica com precisão de $0,1 \mathrm{~g}$. O tempo de secagem variou de 24 a 48 horas; após a secagem o material foi colocado em dessecador contendo sílica gel e pesados. Os resultados foram divididos por 10 (número de frutos) para obtenção da massa seca/fruto, expressa em gramas (g) (LUCENA et. al., 2007).

A massa de água foi determinada por diferença entre a massa fresca (MF) e a massa seca (MS), expressa em grama (g) (LUCENA et. al., 2007). O teor de água foi determinado através da seguinte equação:

Teor de água=massa de água $\mathrm{x} \mathrm{MF}^{-1-1}$ x 100 ,

expresso em porcentagem $(\%)$.

em que:

$\mathrm{MF}=$ massa fresca dos frutos, $\mathrm{g}$.

Os sólidos solúveis totais (SST) foram determinados usando-se um refratômetro digital Rieichrt, com variação de 0 a $62{ }^{\circ}$ Brix, com compensação de temperatura automática (AOAC, 2005). A acidez total titulável (ATT) determinada por titulometria e os resultados expressos em percentagem (\%) de ácido cítrico na massa fresca (BRASIL, 2005). Determinou-se o pH em potenciômetro digital com eletrodo de membrana de vidro (AOAC, 2005). A relação 
SST/ATT foi obtida através do quociente entre as duas variáveis

$\mathrm{O}$ teor de amido foi determinado em $5,0 \mathrm{~g}$ da amostra, segundo a metodologia descrita em Aoac (2005), para a leitura a $540 \mathrm{~mm}$, utilizou-se alíquota de $0,2 \mathrm{~mL}$, no qual determinou-se os açúcares redutores pelo método do DNS (ácido dinitrosalicílico), conforme Miller (1959), os resultados obtidos foram multiplicados por 0,9 para obtenção da percentagem (\%) de amido em massa fresca. Os açúcares solúveis totais (AST) foram determinados em amostras de 1,0 $\mathrm{g}$ de polpa, de acordo com metodologia de Yemn e Willis (1954) e os resultados expressos em percentagem (\%) da massa fresca. Quanto à análise dos açúcares redutores (AR), a extração foi feita em água destilada e determinada segundo Miller (1959), seguida da leitura em espectrofotômetro a 540 $\mathrm{nm}$, e os resultados foram expressos em percentagem (\%) da massa fresca. Os açúcares não redutores (ANR) foram obtidos por diferença entre os açúcares solúveis totais (AST) e os redutores (AR); os resultados foram expressos em percentagem (\%) da massa fresca da polpa.

A vitamina $\mathrm{C}$ foi determinada através da titulometria com solução de DCFI (2,6-diclorofenolindofenol sódio 0,02\%) de acordo com Strohecker e Henning (1967), os resultados foram expressos em $\mathrm{mg}$ de ácido ascórbico/100 g da massa fresca da polpa.

As pectinas total e solúvel foram extraídas em aproximadamente $2,5 \mathrm{~g}$ da polpa homogeneizada em etanol a $95 \%$, segundo procedimento descrito por McReady e McComb (1952). A hidrólise foi realizada segundo recomendações de Blumenkrantz e Asboe-Hansen (1973) e os resultados expressos em $\mathrm{mg}$ de pectina por $100 \mathrm{~g}$ da massa fresca da polpa. Obteve-se a percentagem de solubilização de pectina através do quociente entre o conteúdo de pectina solúvel e da pectina total.

A extração dos fenólicos foi realizada de acordo com Swain e Hillis (1959), utilizando-se aproximadamente 5,0 g da amostra com $50 \mathrm{~mL}$ do líquido extrator (metanol a $99,5 \%$ para formas dímeras; metanol a $50 \%$ para as formas oligoméricas e água destilada para as formas poliméricas). Para o doseamento utilizou-se a metodologia descrita por Reicher et al. (1981); e os resultados expressos em mg/100 g da massa fresca.

As antocianinas totais foram determinadas segundo a metodologia descrita por Francis (1982); a extração foi realizada utilizando-se $1,0 \mathrm{~g}$ da amostra, os resultados expressos em mg/100 g. A quantificação dos flavonoides amarelos seguiu a metodologia descrita por Francis (1982), e com o filtrado obtido na determinação das antocianinas totais realizou-se a leitura em espectrofotômetro a $374 \mathrm{~nm}$, os resultados, expressos em $\mathrm{mg} / 100 \mathrm{~g}$ de massa fresca. Os carotenoides totais foram determinados pelo método de Lichtenthaler (1987), os resultados expressos em mg/100 g da massa fresca da polpa.

A análise dos dados foi realizada usando-se a estatística descritiva com quatro repetições, através do Programa Computacional Assistat versão 7.6 Beta.

\section{RESULTADOS E DISCUSSÃO}

Os frutos de murta apresentaram coloração $100 \%$ violeta, que corresponde conforme The New Munsell Student Color Set (MUNSELL, 1994), Croma 2, Valor 2,5 e Ângulo Hue 5P. De acordo com Mendoza e Aguilera (2004) a coloração é uma característica muito usada para classificação dos frutos no processo do amadurecimento, nas quais são observados principalmente o estádio de maturação e o ponto de colheita.

Na Tabela 1 são apresentados os dados relativos às características físicas dos frutos da murta (Eugenia gracillima Kiaersk.) no estádio de maturação "maduro".

Os diâmetros longitudinal (DL) e transversal (DT) dos frutos foram, respectivamente, 10,13 e 9,76 mm. Resultados estes que estão dentro da faixa encontrada por Borges et al. (2010) no seu estudo sobre o rendimento da polpa e morfometria dos frutos e sementes de pitangueira do cerrado, cujos frutos apresentaram valores de 8 a $20 \mathrm{~mm}$ de largura e de 10 a $30 \mathrm{~mm}$ de comprimento. Dias et al. (2011) verificou diâmetros superiores aos da murta, 15,19 $\mathrm{mm}$ DL e $10,78 \mathrm{~mm}$ DT em frutos da pitangueira.

Os resultados dos DL e DT indicam que o tamanho dos frutos da murta é relativamente pequeno. Observou-se pouca diferença entre os diâmetros dos frutos, sendo o DL superior ao DT, indicando que a murta apresentou frutos com formato levemente ovalado; no entanto, podem-se observar diferenças na forma dentro da mesma espécie estudada, com frutos se apresentando também na forma arredondada.

Tabela 1. Valores médios das características físicas dos frutos da murta (Eugenia gracillima Kiaersk.) no estádio de maturação "maduro".

\begin{tabular}{lcc}
\hline Características físicas & Média \pm Desvio padrão & CV (\%) \\
\hline Diâmetro longitudinal $(\mathrm{mm})$ & $10,13 \pm 0,37$ & 3,66 \\
Diâmetro transversal $(\mathrm{mm})$ & $9,76 \pm 0,48$ & 4,90 \\
Massa fresca $(\mathrm{g})$ & $0,78 \pm 0,04$ & 5,50 \\
Massa seca $(\mathrm{g})$ & $0,31 \pm 0,02$ & 7,99 \\
Massa de água $(\mathrm{g})$ & $0,46 \pm 0,03$ & 6,24 \\
Teor de água $(\%)$ & $59,80 \pm 2,18$ & 3,64 \\
\hline
\end{tabular}

Com relação à massa fresca (MF), massa seca (MS), massa de água (MA) e teor de água, os frutos de murta no estádio de maturação "maduro" apresentaram valores de 0,78 , 031, 046 g e 59,80\%, respectivamente. Santos et al. (2004) verificaram, ao determinarem o teor de água em seis espécies de myrtaceae nativas do Rio Grande do Sul, valores entre 40 a 86\% de água, nas espécies: Acca sellowiana (Berg.) Burret.
(76\%), Campomanesia guazumifolia (Camb.) Berg. (78\%), Campomanesia xanthocarpa Berg. (83\%), Eugenia rostrifolia Legr. (43\%), Myrcianthes pungens (Berg.) Legr. (40\%) e Psidium cattleyanum Sabine (86\%).

As características físicas, químicas ou físicoquímicas dos frutos podem ser influenciadas por vários fatores, além das próprias cultivares, tratos culturais (HOJO et 
al., 2007). Os índices pluviométricos (SOUZA et al., 2010) e o estádio de maturação (AZZOLINI et al., 2004; CAVALINI et al., 2006), entre outros, também são fatores determinantes na variação dessas características.

Na Tabela 2 são apresentados os dados relativos às características químicas e físico-químicas dos frutos da murta (Eugenia gracillima Kiaersk.) no estádio de maturação "maduro".

Os frutos da murta apresentaram teor médio dos sólidos solúveis totais (SST) de 15,08 ºrix, este parâmetro, segundo Chaves et al. (2004) é utilizado como índice de maturidade em alguns frutos, de forma que indicam as substâncias neles dissolvidas, que são constituídas principalmente de açúcares. Rufino (2008) verificou, em frutos da murta (Blepharocalyx salicifolius (H.B.K.) Berg) teor de $20,73{ }^{\circ}$ Brix, valor este superior ao encontrado neste trabalho. Enquanto, Silva et al. (2009) observaram em frutos de cajaranazeira maduros em torno de 12,0 ${ }^{\circ}$ Brix, e
Gonçalves et al. (2006) 13,0 ${ }^{\circ}$ Brix em frutos de filgueiras. Canuto et al. (2010) verificaram, em frutos colhidos fisiologicamente maturos, teores de 12,0 e $18,0{ }^{\circ}$ Brix em graviola e açaí, respectivamente.

Com relação à acidez total titulável (ATT) e ao pH, os frutos obtiveram um teor de $0,82 \%$ de ácido cítrico e 3,73, respectivamente. O teor da ATT nos frutos determinados neste trabalho foi próximo ao determinado por Zillo et al. (2013) em uvaias, superior ao encontrado por Rufino (2008), que verificou $0,64 \%$ de ATT em frutos da murta (Blepharocalyx salicifolius (H.B.K.) Berg), e inferiores ao verificado por Adriano et al. (2011) em acerolas maduras $(3,15 \%)$. Valor de $\mathrm{pH}$ próximo ao da murta foram determinados por Santos et al. (2009) em frutos de gabiroba ( $\mathrm{pH}$ de 3,89), e por Coutinho et al. (2013) em frutos de cambuí (pH de 3,9). Lima et al. (2013) reportaram, em espécies de pitaias o $\mathrm{pH}$ variando de 4,84 a 5,67 e, Vallilo et al. (2005) $\mathrm{pH}$ de 2,91 para frutos do cambucizeiro.

Tabela 2. Valores médios das características químicas e físico-químicas dos frutos da murta (Eugenia gracillima Kiaersk.) no estádio de maturação "maduro".

\begin{tabular}{|c|c|c|}
\hline Características químicas e físico-químicas & Média \pm Desvio padrão & $\mathrm{CV}(\%)$ \\
\hline Sólidos solúveis totais $\left({ }^{\circ} \mathrm{Brix}\right)$ & $15,08 \pm 0,17$ & 1,13 \\
\hline Acidez total titulável (\% de ácido cítrico) & $0,82 \pm 0,05$ & 5,56 \\
\hline $\mathrm{pH}$ & $3,73 \pm 0,01$ & 0,15 \\
\hline Relação SST/ATT & $18,37 \pm 1,00$ & 5,46 \\
\hline Amido $(\%)$ & $3,73 \pm 0,03$ & 0,78 \\
\hline Açúcares solúveis totais (\%) & $11,61 \pm 0,37$ & 3,17 \\
\hline Açúcares redutores $(\%)$ & $7,80 \pm 0,20$ & 2,61 \\
\hline Açúcares não redutores (\%) & $3,81 \pm 0,34$ & 9,05 \\
\hline Vitamina $\mathrm{C}(\mathrm{mg} / 100 \mathrm{~g}$ de $\mathrm{mff})$ & $160,62 \pm 12,77$ & 7,95 \\
\hline Pectina total (mg/100 g de $\mathrm{mff})$ & $612,66 \pm 5,95$ & 0,97 \\
\hline Pectina solúvel (mg/100 g de mff) & $116,88 \pm 6,09$ & 5,21 \\
\hline Solubilização de pectina (\%) & $19,10 \pm 1,38$ & 7,20 \\
\hline Fenólicos dímeros (mg/100 g de mff) & $605,03 \pm 12,62$ & 2,09 \\
\hline Fenólicos oligoméricos (mg/100 g de mff) & $788,66 \pm 13,88$ & 1,76 \\
\hline Fenólicos poliméricos (mg/100 g de mff) & $247,20 \pm 14,88$ & 6,02 \\
\hline Antocianinas (mg/100 g de $\mathrm{mff})$ & $125,82 \pm 2,08$ & 1,65 \\
\hline Flavonoides amarelos (mg/100 g) & $69,53 \pm 0,36$ & 0,51 \\
\hline Carotenoides $(\mathrm{mg} / 100 \mathrm{~g})$ & $129,77 \pm 0,93$ & 0,72 \\
\hline
\end{tabular}

* mff = massa fresca do fruto

A relação SST/ATT é mais representativa que a medição isolada de açúcares ou da acidez, os frutos da murta no estádio de maturação estudado neste trabalho apresentaram uma relação SST/ATT de 18,37, resultados estes que indicam frutos com ótima qualidade para consumo. Contudo, valores superiores da relação SST/ATT foram relatados por Rufino (2008) ao verificar em frutos da murta (Blepharocalyx salicifolius (H.B.K.) Berg) uma relação de 32,60. E valores inferiores $(9,10)$ foram observados por Melo et al. (2013) em frutos de araçá no estádio de maturação amarelado e, por Dias et al., (2011) em diferentes genótipos de pitanga madura (média de 5,85).

Os valores dos teores dos carboidratos (amido, açúcares solúveis totais, açúcares redutores e açúcares não redutores) nos frutos da murta foram, respectivamente, 3,73, $11,61,7,80$ e $3,81 \%$. Resultados semelhantes obtiveram Ferreira et al. (2009), verificando em acerolas no estádio de maturação 6 o conteúdo de açúcares solúveis totais em torno de $12,43 \%$. Adriano et al. (2011) determinaram em acerolas $5,73 \%$ de açúcares redutores, conteúdo inferior ao encontrado neste trabalho para os frutos da murta. Asquieri et al. (2004), obtiveram teores de açúcares totais, redutores e não redutores de $11,2,9,3$ e $1,9 \mathrm{~g}$ em $100 \mathrm{~g}$ de polpa de jabuticaba, respectivamente.

O teor de vitamina $\mathrm{C}$ nos frutos da murta no estádio de maturação "maduro" foi de 160,62 mg/100 g, conteúdo este que indica que os frutos são ricos em vitamina $C$. Resultados semelhantes foram observados por Rufino (2008) quando estudando as propriedades funcionais de frutas tropicais brasileiras não tradicionais, verificaram em frutos da murta (Blepharocalyx salicifolius (H.B.K.) Berg) 181,1 mg de ácido ascórbico/100 g de massa fresca. Genovese et al. (2008) avaliando o conteúdo de ácido ascórbico em algumas espécies da família Myrtaceae do estado de São Paulo, reportaram 9,5, 397,0 e 4,8 mg/100 g para araçá-boi, camu-camu e araçá, respectivamente.

O conteúdo de pectina total (PT) foi de 612,66 $\mathrm{mg} / 100 \mathrm{~g}$ de massa fresca do fruto e $116,88 \mathrm{mg} / 100 \mathrm{~g}$ de pectina solúvel (PS). A percentagem de solubilização de pectina foi $19,10 \%$. Rufino (2008) reportou em frutos da murta (Blepharocalyx salicifolius (H.B.K.) Berg) valores 
próximos aos determinados neste trabalho, $670,0 \mathrm{mg} / 100 \mathrm{~g}$ de PT e $100,0 \mathrm{mg} / 100 \mathrm{~g}$ de PS.

Com relação aos fenólicos dímeros (FD), oligoméricos (FO) e poliméricos (FP), os frutos de murta apresentaram teores de 605,03, 788,66 e 247,20 mg/100 g de massa fresca da polpa, respectivamente. O somatório dos valores médios dos compostos fenólicos desta pesquisa, totaliza 1.604,89 mg/100 g da massa fresca da polpa. Valores inferiores foram verificados por Tosun et al. (2008) em frutos de amora preta maduros $(936,82 \mathrm{mg} / 100 \mathrm{~g})$. Jáuregui et al. (2007) verificaram em camu-camu (Myrciaria dubia) e maracujá (Passiflora mollisima), valores de 2.393,72, $1.478,26 \mathrm{mg} / 100 \mathrm{~g}$ de peso fresco, respectivamente.

Quanto à forma dos compostos fenólicos, foram verificados maiores conteúdos das formas oligoméricas, seguidas das formas dímeras e menores valores das formas poliméricas. Fetter et al. (2010) quantificaram os compostos fenólicos para espécies da família Myrtaceae, indicando potencial antioxidante para esses frutos.

$\mathrm{O}$ teor de antocianinas totais, flavonoides amarelos e carotenoides totais foi de 125,82, 69,53 e 129,76 mg/100g da massa fresca do fruto indicando potencial antioxidante para esses frutos. O conteúdo de antocianinas totais está dentro da faixa obtida por Mota (2006) para polpa de frutos de sete cultivares de amora-preta, como também ao determinado por Bagetti et al. (2011) em polpa de frutos de pitanga roxa $(136,6 \mathrm{mg} / 100 \mathrm{~g})$. Com relação ao teor de flavonoides amarelos, Rufino et al. (2010) reportaram para polpa de frutos de murta (Blepharocalyx salicifolius) 207,0 mg/100g, valor inferior ao encontrado neste trabalho. Quanto aos carotenoides totais, os frutos de murta possuem conteúdo superior aos reportados por Piña-Dumoulín et al. (2010) para a pitanga, os frutos de cor vermelho-alaranjado, vermelhos com maior proporção de polpa e vermelhos com maior proporção de casca, apresentaram 23,64, 10,91 e 33,77 $\mathrm{mg} / 100 \mathrm{~g}$ de carotenoides, repectivamente.

\section{CONCLUSÕES}

Com base nos resultados obtidos e para as condições em que o trabalho foi desenvolvido, conclui-se que os frutos da murta (Eugenia gracillima Kiaersk.) são relativamente pequenos com formato levemente ovalado, possuindo também na forma arredondada, com coloração $100 \%$ violeta quando maduros, e apresentam ótima qualidade para consumo pelo conteúdo dos sólidos solúveis totais, relação SST/ATT, açúcares solúveis totais e açúcares redutores, como também são frutos ricos em vitamina $\mathrm{C}$ e antioxidantes.

\section{REFERÊNCIAS BIBLIOGRÁFICAS}

ADRIANO, E.; LEONEL, S.; EVANGELISTA, R. M. Qualidade de fruto da aceroleira cv. olivier em dois estádios de maturação. Revista Brasileira de Fruticultura, Jaboticabal, v.33, n.spe1, p.541-545, 2011.

AOAC - Association of Official Analytical Chemists. Official methods of analysis of AOAC International. $18 \mathrm{ed}$., Gaithersburg, Maryland: AOAC International, 2005. 1219 p.
ASQUIERI, E. R.; CANDIDO, M. A.; DAMIANI, C.; ASSIS, E. M. Fabricación de vino blanco y tinto de jabuticaba (Myrciaria jaboticaba berg) utilizando la pulpa y la cáscara respectivamente. Alimentaria, (Madrid) España, v.355, n.1, p.97-109. 2004.

AZZOLINI, M.; JACOMINO, A. P.; BRON, I. U. Índices para avaliar qualidade pós-colheita de goiabas em diferentes estádios de maturação. Pesquisa Agropecuária Brasileira, Brasília, v.39, n.2, p.139-145, 2004.

BAGETTI, M.; FACCO, E. M. P.; PICCOLO, J.; HIRSCH, G. E.; RODRIGUEZ-AMAYA, D.; KOBORI, C. N.; VIZZOTO, M.; EMANUELLI, T. Physicochemical characterization and antioxidant capacity of pitanga fruits (Eugenia uniflora L.). Ciência e Tecnologia de Alimentos, Campinas, v.31, n.1, p.147-154, 2011.

BLUMENKRANTZ, N.; ASBOE-HANSEN, G. New method for quantitative determination of uronic acids. Analytical Biochemistry, New York, v.54, n.2, p.484489, 1973.

BORGES, K. C. F.; SANTANA, D. G.; MELO, B.; SANTOS, C. M. Rendimento de polpa e morfometria de frutos e sementes de pitangueira-do-cerrado. Revista Brasileira de Fruticultura, Jaboticabal, v.32, n.2, p.471-478, 2010.

BRASIL. Ministério da Saúde. Agência Nacional de Vigilância Sanitária (ANVISA). Métodos FísicoQuímicos para Análise de Alimentos. Brasília: Ministério da Saúde, 2005. 1018p.

CAMPOS, R. P.; KNOCH, B.; HIANE, P. A.; RAMOS, M. I. L.; RAMOS FILHO, M. M. 1-MCP em mangabas armazenadas em temperatura ambiente e a $11^{\circ} \mathrm{C}$. Revista Brasileira de Fruticultura, Jaboticabal, v.33, n.spe1, p.206-212, 2011.

CANUTO, G. A. B.; XAVIER, A. A. O.; NEVES, L. C.; BENASSI, M. T. Caracterização físico-química de polpas de frutos da Amazônia e sua correlação com a atividade anti-radical livre. Revista Brasileira de Fruticultura, Jaboticabal, v.32, n.4, p.1196-1205, 2010.

CAVALINI, F. C.; JACOMINO, A. P.; LOCHOSKI, M. A.; KLUGE, R. A.; ORTEGA E. M. M. Maturity indexes for "Kumagai" and "Paluma" guavas. Revista Brasileira de Fruticultura, Jaboticabal, v.28, n.2, p.176-179, 2006.

CHAVES, M. C. V; GOUVEIA, J. P. G.; ALMEIDA, F. A. C.; LEITE, J. C. A.; SILVA, F. L. H. Caracterização físico-química do suco da acerola. Revista de Biologia e Ciências da Terra, Campina Grande, v.4, n.2, p.1-10, 2004.

COUTINHO, H. D. M.; SILVA, I.; FREITAS M. A.; GONDIM, C. N. F. L.; ANDRADE, J. C. Análise físicoquímica e avaliação antimicrobiana do fruto cambuí 
(Myrcia multiflora). Biofar: Revista de Biologia e Farmácia, Campina Grande, v.9, n.1, p.96-103, mar/mai. 2013.

CUNHA JÚNIOR, L. C.; DURIGAN, M. F. B.; MATTIUZ, B. Conservação de pêssego 'Aurora-1' armazenados sob refrigeração. Revista Brasileira de Fruticultura, Jaboticabal, v.32, n.2, p.386-396, 2010.

DIAS, T. C.; MOTA, W. F.; OTONI, B. S.; MIZOBUTSI, G. P.; SANTOS, M. G. P. Conservação pós-colheita de mamão Formosa com filme de PVC e refrigeração. Revista Brasileira de Fruticultura, Jaboticabal, v.33, n.2, p.666-670, 2011.

FERREIRA, R. M. A.; AROUCHA, E. M. M.; SOUZA, P. A.; QUEIROZ, R. F.; FILHO, F. S. T. P. Ponto de colheita da acerola visando à produção industrial de polpa. Revista Verde de Agroecologia e Desenvolvimento Sustentável, Mossoró, v.4, n.2, p.1316, 2009.

FETTER, M. R.; VIZZOTTO, M.; CORBELINI, D. D.; GONZALEZ, T. N. Propriedades funcionais de araçáamarelo, araçá-vermelho (Psidium cattleyanum Sabine) e araçá-pera ( $P$. acutangulum D.C.) cultivados em Pelotas/RS. Brazilian Journal of Food Technology, III SSA, 2010.

FRANCIS, F. J. Analysis of anthocyanins. In: Markakis, P. (Ed.). Anthocyanins as food colors. New York: Academic, 1982. p.181-207.

GENOVESE, M. I.; PINTO, M. S.; GONÇALVES, A. E. S. S.; LAJOLO, F. M. Bioactive compounds and antioxidant capacity of exotic fruits and commercial frozen pulps from Brazil. Food Science and Technology International, v.14, n.3, p.207-214, 2008.

GONÇALVES, C. A. A.; LIMA, L. C. O.; LOPES, P. S. N.; PRADO, M. E. T. Caracterização física, físico-química, enzimática e de parede celular em diferentes estádios de desenvolvimento da fruta de figueira. Ciência e Tecnologia de Alimentos, Campinas, v.26, n.1, p.220229. 2006.

HOJO, R. H.; CHALFUN, N. N. J.; DOLL HOJO, E. T.; VEIGA, R. D.; PAGILS, C. M.; LIMA, L. C. O. Produção e qualidade dos frutos da goiabeira 'Pedro Sato' submetida a diferentes épocas de poda. Pesquisa Agropecuária Brasileira, Brasília, v.42, n.3, p.357-362, 2007.

JÁUREGUI, A. M. M.; RAMOS-ESCUDERO, D. F.; URETA, C. A. O.; CASTAÑEDA, B. C. Evaluación de la capacidad antioxidante y contenido de compuestos fenólicos em recursos vegetales promisorios. Revista de la Sociedad Química del Perú, Peru, v.73, n.3, p.142$149,2007$.

LICHTENTHALER, H. K. Chlorophylls and carotenoids: pigments of photosynthetic biomembranes. In:
PACKER, L., DOUCE, R. (Eds.) Methods in Enzimology. London: Academic Press, 1081. v.148, 1987, p.350-81.

LIMA, C. A., FALEIRO, F. G., JUNQUEIRA, N. T. V., COHEN, K. O., GUIMARÃES, T. G. Características físico-químicas, polifenóis e flavonoides amarelos em frutos de espécies de pitaias comerciais e nativas do cerrado. Revista Brasileira de Fruticultura, Jaboticabal, v.35, n.2, p.565-570, 2013.

LUCENA, E. M. P.; ASSIS, J. S.; ALVES, R. E.; SILVA, V. C. M.; FILHO, J. E. Alterações físicas e químicas durante o desenvolvimento de mangas 'Tommy Atkins' no vale de São Francisco, Petrolina-PE. Revista Brasileira de Fruticultura, Jaboticabal, v.29, n.1, p.96$101,2007$.

MCREADY, P. M.; MCCOMB, E. A. Extraction and determination of total pectin materials. Analytical Chemistry, Washington, v.24, n.12, p.1586-1588, 1952.

MELO, A P. C., SElEGUINI, A.; VELOSO, V. R. S. Caracterização física e química de frutos de araçá (Psidium guineense Swartz). Comunicata Scientiae, Bom Jesus, v.4, n.1, p.91-95. 2013.

MENDOZA, F.; AGUILERA, J. M. Application of image analysis for classification of ripening bananas. Journal of Food Science, New York, v.69, n.9, p.471-477, 2004.

MILLER, G. L. Use of dinitrosalicylic acid reagent for determination of reducing sugars. Analytical Chemistry, Washington, v.31, n.3, p.426-428, 1959.

MOTA, R. V. Caracterização física e química de geleia de amora-preta. Ciência e Tecnologia de Alimentos, Campinas, v.26, n.3, p.39-543, 2006.

MUNSELl, A. H. The New Munsell Student Color Set. Fairchild Publication, New York, 1994. 17p.

PIÑA-DUMOULÍN, G.; OCHOA, A.; MAGAÑA-LEMUS, S. Caracterización físico-química de frutas frescas de cultivos no tradicionales en Venezuela. II. La Pitanga. Agronomía Tropical, Maracay, v.60, n.2, p.203-209, 2010.

REICHER, F.; SIERAKOWSKI, M. R.; CORREA, J. B. C. Determinação espectrofotométrica de taninos pelo reativo fosfotúngstico-fosfomolíbdico. Arquivos de Biologia e Tecnologia, Curitiba, v.24, n.4, p.407-411. 1981.

RUFINO, M. S. M. Propriedades funcionais de frutas tropicais brasileiras não tradicionais. Mossoró: Universidade Federal Rural do Semiárido, 2008. 237p. Tese Doutorado.

RUFINO, M. S. M.; ALVES, R. E.; BRITO, E. S.; PÉREZJIMÉNEZ J.; SAURA-CALIXTO, F.; MANCINIFILHO, J. Bioactive compounds and antioxidant 
capacities of 18 non-traditional tropical fruits from Brazil. Food Chemistry, Kidlington, v.121, n.4, p.9961002, 2010.

SANTOS, C. M. R.; FERREIRA, A. G.; ÁQUILA, M. E. A. Características de frutos e germinação de sementes de seis espécies de Myrtaceae nativas do Rio Grande do Sul. CiênciaFlorestal, Santa Maria, v.14, n.2, p.13-20, 2004.

SANTOS, M. S.; CARNEIRO, P. I. B.; WOSIACKI G.; PETKOWICZ, C. L. O.; CARNEIRO, E. B. B Caracterização físico-química, extração e análise de pectinas de frutos de Campomanesia Xanthocarpa B. (Gabiroba). Semina: Ciências Agrárias, Londrina v.30, n.1, p.101-106, 2009.

SILVA, G. G.; MORAIS, P. L. D.; ROCHA, R. H. C. SANTOS, E. C.; SARMENTO, J. D. A. Caracterização do fruto de cajaranazeira em diferentes estádios de maturação. Revista Brasileira de Produtos Agroindustriais, Campina Grande, v.11, n.2, p.159163,2009

SOUZA, M. E.; SILVA, A. C.; SOUZA, A. P.; TANAKA, A. A.; LEONEL, S. Influência das precipitações pluviométricas em atributos físico-químicos de frutos da goiabeira "Paluma" em diferentes estádios de maturação. Revista Brasileira de Fruticultura, Jaboticabal, v.32, n.2, p.637-646, 2010.
STROHECKER, R.; HENNING, H. M. Analisis de vitaminas: Métodos comprobados. Madrid: Paz Montalvo, 1967. 428 p.

SWAIN, T.; HILLIS, E. E. The phenolic constituents of Prunus domestica: II. The analysis of tissues of the 'victoria' plum tree. Journal of the Science of Food and Agriculture, London, v.10, n.2, p.135-144, 1959.

TOSUN, I.; USTUN, N.S.; TEKGULER, B. Mudanças físicas e químicas durante a maturação de frutos de amora preta. Scientia Agricola, Piracicaba, v.65, n.1, p.87-90, 2008.

VALLILO, M.I.; GARBELOTTI, M.L.; OLIVEIRA, E.; LAMARDO, L. C. A. Características físicas e químicas dos frutos do cambucizeiro (Campomanesia phaea). Revista Brasileira de Fruticultura, Jaboticabal, v.27, n.2, p.241-244, 2005.

YEMN, E.W.; WILLIS, A.J. The estimation of carbohydrate in plant extracts by anthrone. The Biochemical Journal, London, v.57, n.3, p.508-514, 1954.

ZILLO, R. R.; SILVA, P. P. M., ZANATTA, S.; CARMO, L. F.; SPOTO, M. H. F. Qualidade físico-química da fruta in natura e da polpa de uvaia congelada. Revista Brasileira de Produtos Agroindustriais, Campina Grande, v.15, n.3, p.293-298, 2013. 